\title{
Maintenance Efficacy of Divalproex in the Prevention of Bipolar Depression
}

\author{
Laszlo Gyulai*,', Charles L Bowden ${ }^{2}$, Susan L McElroy ${ }^{3}$, Joseph R Calabrese ${ }^{4}$, Frederick Petty ${ }^{5}$, Alan C \\ Swann $^{6}$, James C-Y Chou $^{7,8}$, Adel Wassef ${ }^{6}$, Craig S Risch ${ }^{9}$, Robert MA Hirschfeld ${ }^{10}$, Charles B Nemeroff' , \\ Paul E Keck Jr ${ }^{3}$, Dwight L Evans', and Patricia J Wozniak ${ }^{\prime 2}$ \\ 'Department of Psychiatry, University of Pennsylvania, Philadelphia, PA, USA; '2 University of Texas Health Science Center, San Antonio, TX, USA; \\ ${ }^{3}$ University of Cincinnati College of Medicine, Cincinnati, OH, USA; ${ }^{4}$ Case Western University School of Medicine, Cleveland, $\mathrm{OH}, \mathrm{USA} ;{ }^{5} \mathrm{Creighton}$ \\ University, Omaha, NE, USA; ${ }^{6}$ University of Texas Health Science Center-Houston, Houston, TX, USA; ${ }^{7}$ Bellevue Hospital Center, NYU School of \\ Medicine, New York, NY, USA; ${ }^{8}$ Nathan Kline Institute, Orangeburg, NY, USA; ${ }^{9}$ University of California at San Francisco, San Francisco, CA, USA; \\ ${ }^{10}$ University of Texas Medical Branch, Galveston, TX, USA; "'Emory University School of Medicine, Atlanta, GA, USA; ${ }^{12}$ Abbott Laboratories, \\ North Chicago, IL, USA
}

\begin{abstract}
Breakthrough depression is a common problem in the treatment of bipolar disorder. Only one, recently published, double-blind, placebo-controlled trial has examined the efficacy of divalproex in the prevention of depressive episodes in bipolar patients. This report describes, in further detail, the findings from that trial of the effect of divalproex on multiple dimensions of depressive morbidity in bipolar disorder. A randomized, double-blind, parallel-group, multicenter study was conducted over a 52-week maintenance period. Bipolar I patients, who may have been treated with open-label lithium or divalproex and who met recovery criteria within 3 months of onset of an index manic episode, were randomized to maintenance treatment with divalproex, lithium, or placebo in a $2:$ I: I ratio. Adjunctive paroxetine or sertraline for breakthrough depression was allowed in maintenance phase. Outcome measures were the rate of early discontinuation for depression, time to depressive relapse, proportion of patients with depressive relapse, mean change in Depressive Syndrome Scale score, proportion of patients receiving antidepressants, and time in the study. Among patients taking an antidepressant, a higher percentage of patients on placebo than divalproex discontinued early for depression. Patients who were previously hospitalized for affective episodes or took divalproex in the open period relapsed later on divalproex than on lithium during the maintenance period. Divalproex-treated patients had less worsening of depressive symptoms than lithium-treated patients during maintenance. Indices of severity of prestudy illness course predicted worse outcome in all treatment groups. Divalproex improved several dimensions of depressive morbidity and reduced the probability of depressive relapse in bipolar disorder, particularly in patients who had responded to divalproex when manic, and among patients with a more severe course of illness.
\end{abstract}

Neuropsychopharmacology (2003) 28, 1374-1382, advance online publication, 28 May 2003; doi: I0.1038/sj.npp. 1300190

Keywords: divalproex; bipolar disorder; bipolar depression; maintenance treatment; selective serotonin uptake inhibitor (SSRI); valproic acid

\section{INTRODUCTION}

Breakthrough depression is a common problem in the treatment of bipolar disorder. Double-blind, placebo-controlled studies conducted during the 1970s demonstrated that lithium was more effective than placebo at preventing recurrences of bipolar depression (Prien et al, 1973a; Fieve et al, 1976; Goodwin and Jamison, 1990). A later, naturalistic study revealed that approximately $30 \%$ of lithium-treated bipolar patients experienced depressive

*Correspondence: Dr L Gyulai, Department of Psychiatry, University of Pennsylvania Medical Center, Mood and Anxiety Disorders Section, 3535 Market St., 6th Floor, Philadelphia, PA 19104, USA, Tel: + I 215 746 64I5, E-mail: gyulai@mail.med.upenn.edu

Received 03 September 2002; revised 23 December 2002; accepted 08 January 2003

Online publication: 12 March 2003 at http://www.acnp.org/citations/ Npp03 | 202330/default.pdf relapse yearly (O'Connell et al, 1991). Lithium has been found to be more effective in the maintenance treatment of 'classical' rather than 'nonclassical' bipolar disorder (Greil et al, 1998), and less effective in rapid cycling, for which several anticonvulsants appear to be more effective (Dunner and Fieve, 1974; Bauer et al, 1994; Calabrese et al, 2000). Antidepressants are frequently prescribed for bipolar depression prophylaxis (Zarate et al, 1995); however, their use is controversial because they may induce mood destabilization (Altshuler et al, 1995). Therefore, additional medications to prevent breakthrough depression and reduce depressive morbidity are needed. Valproate may be useful in acute and prophylactic treatment of bipolar depression (Petty et al, 1999; Puzynski and Klosiewicz, 1984; Emrich et al, 1983). In open-label maintenance trials (McElroy et al, 1988; Calabrese and Delucchi, 1990; Ghaemi and Goodwin, 2001), valproate treatment reduced depressive symptoms in bipolar patients. 
We previously reported the results of the first multicenter, double-blind, placebo-controlled trial comparing divalproex, lithium, and placebo for the prevention of affective episodes in bipolar I patients (Bowden et al, 2000), presenting preliminary evidence that divalproex ameliorated depressive morbidity. This paper presents additional analyses from that study, including a comparison of the maintenance efficacy of divalproex, lithium, or placebo for bipolar depression. We hypothesized that divalproex would be more effective than placebo or lithium in reducing depressive morbidity of bipolar patients, especially those with a more severe course of illness prior to study entry because severity of illness course (number of previous affective episodes and/or hospitalizations) has been shown to reduce the effectiveness of lithium (Swann et al, 1999, 2000; Prien et al, 1974; Maj et al, 1998; Gelenberg et al, 1989), but not of divalproex (Swann et al, 1999, 2000).

\section{PATIENTS AND METHODS}

Methodology for this study has previously been described in detail (Bowden et al, 2000).

\section{Patients}

Patients between 18 and 75 years old with bipolar disorder type I, confirmed by the Structured Clinical Interview for DSM-III-R (Spitzer et al, 1990), were eligible for enrollment in the study. All patients experienced a manic episode (index episode) $\leqslant 3$ months before randomization and at least one additional episode within 3 years before study entry. Patients with a history of substance dependence, substance abuse within 6 months before study entry, or severe medical conditions were excluded. Patients provided written informed consent for study participation. The study was approved by the Institutional Review Boards of each participating center.

\section{Experimental Design}

This was a randomized, double-blind, placebo-controlled, parallel-design, multicenter study that was comprised of two periods. The first was an open-label period that lasted up to 90 days, which was followed by a 52 -week randomized maintenance period. During the open-label period, the index manic episode was stabilized with the investigator's choice of medication(s). Psychotropic medications, other than lithium or valproate, were discontinued before randomization. At the end of the open-label treatment period, eligible patients were randomized, in a $2: 1: 1$ ratio, to divalproex $(n=187)$, lithium $(n=91)$, or placebo $(n=94)$. Randomization requirements included a Global Assessment Scale (GAS) score $>60$, a Mania Rating Scale (MRS) score (derived from the Schedule for Affective Disorders-Change Version (SADS-C)) (Endicott and Spitzer, 1978) $\leqslant 11$, and a Depressive Syndrome Scale (DSS) score (derived from SADS-C) $<14$. All criteria had to be met on two consecutive visits, at least 6 days apart.

During the first 2 weeks of the maintenance period, openlabel divalproex or lithium was withdrawn concomitantly with the upward dosage titration of the blinded medications (to achieve serum trough concentrations of $71-125 \mathrm{mg} / \mathrm{l}$ for valproate and $0.8-1.2 \mathrm{mEq} / \mathrm{l}$ for lithium). Patients were seen weekly for the first 6 weeks, then biweekly until week 12, and monthly thereafter.

Symptom severity was assessed using the DSS and MRS from the SADS-C (Endicott and Spitzer, 1978; Bowden et al, 1994).

During the first month of maintenance therapy, use of lorazepam (for 2 weeks) and, if necessary, haloperidol (during the second week of lorazepam use) was permitted. A second course ( $\leqslant 7$ days) of lorazepam was permitted after the first month. Patients developing depression (DSS score $\geqslant 25$ ) could receive adjunctive sertraline or paroxetine and were permitted to continue in the study.

\section{Efficacy Outcomes}

Outcome measures that were established a priori included rate of early discontinuation for depression, time to depressive relapse, proportion of patients with depressive relapses, mean change in DSS score from baseline, proportion of patients receiving adjunctive antidepressants, and time in the study. A depressive episode was defined by either need for antidepressant treatment (which should have been initiated in patients with a DSS score $\geqslant 25$ ) or early discontinuation for depression (including SADS-C suicide item score $\geqslant 4$, attempted suicide, or hospitalization for depression). This definition of breakthrough depression is not the same as that for a DSM IV episode of major depression (American Psychiatric Association, 1994). The subgroup of patients who received an SSRI was evaluated on a post hoc basis.

\section{STATISTICAL ANALYSES}

All tests were two-tailed; analyses were performed using the SAS System, Version 6 (SAS Institute, 1989). Values of $P \leqslant 0.05$ were considered significant.

Baseline comparability among treatment groups for demographic characteristics was assessed by the overall $\mathrm{F}$ test of the one-way analysis of variance (ANOVA) for age and by Fisher's exact test extended to $\mathrm{R} \times \mathrm{C}$ for gender and race. For psychiatric history variables, comparability among treatment groups was assessed by the Kruskal-Wallis test for age at first manic episode and age at first depressive episode, and by the Cochran-Mantel-Haenszel test of equal row means for the number of prior manic episodes, number of prior depressive episodes, and the number of prior psychiatric hospitalizations. Fisher's exact test was used to test for pairwise group differences in proportion of patients using divalproex or lithium in the open period, hospitalized for the index episode, prematurely discontinuing from the study, and treated with sertraline or paroxetine (selective serotonin reuptake inhibitors, SSRIs) during the study. Number of days that patients used SSRIs and number of days that patients remained in the study was assessed by one-way ANOVA. For patients who used SSRIs, treatment differences in mean change from baseline DSS score to last DSS score prior to first use of SSRIs were evaluated by oneway ANOVA. Treatment differences in mean treatment day at first use of SSRIs were evaluated by one-way ANOVA. 
Survival analysis of time to depressive relapse was performed for the intent-to-treat (ITT) sample (all patients receiving at least one dose of study drug). Life-table methods were used to compare survival curves using the Wilcoxon test because of its sensitivity to early group differences.

Logistic regression was performed for several dichotomous variables, including early discontinuation for depression, occurrence of a depressive episode, and SSRI use. Predictors were treatment group, sex, age, type of manic symptom cluster (classic $v s$ dysphoric) in the open phase, baseline MRS score, baseline DSS score, lifetime number of depressive episodes (categorized 0, 1-5, 6-10, 11-15, 16-20, $>20$ ), lifetime number of manic and depressive episodes, lifetime number of psychiatric hospitalizations (categorized as for depressive episodes), and age at first manic episode. Best subsets selection was used to identify a model based on score statistic (SAS Institute, 1989).

Multiple regression was used to evaluate change from baseline for mean DSS score. Predictors were treatment group, sex, age, type of manic symptom cluster (classic vs dysphoric) in the open phase, baseline MRS score, baseline DSS score, lifetime number of depressive episodes, lifetime number of manic episodes, lifetime number of psychiatric hospitalizations, and age at first manic episode. Best subsets regression was used to identify a model using Mallow's cp statistic (a function of $R^{2}$ ) as the criterion (Draper and Smith, 1981).

\section{RESULTS}

\section{Baseline Demography and Clinical Characteristics}

In all, 571 patients were enrolled in the open phase of the study; and 372 patients were randomized to maintenance treatment. Of the 199 patients who were not randomized, 51 used lithium only, 80 used divalproex only, 28 used both, and 40 used neither in the open study phase. No significant differences existed between randomized treatment groups for age, gender, or baseline clinical characteristics. The mean (SD) age of the study population was 39.2 (11.8) years old with similar numbers of men and women. Approximately half gave a history of 11 to $>20$ manic episodes and depressive episodes, with the first episode at a mean (SD) age of 24.5 (10.6) and 21.5 (10.0) years old, respectively. In all, $61 \%$ had at least one previous psychiatric hospitalization and $18 \%$ were hospitalized for the index manic episode (Bowden et al, 2000).

In the open period, $40 \%$ (149) were treated with divalproex and $38 \%$ (142) with lithium; rates of use of divalproex or lithium did not differ across randomized treatment groups. Additionally, the number of days in the open phase (mean of 36.4 days across treatment groups) and the number of days from onset of the index episode to randomization (mean of 74.1 days across treatment groups) were equivalent in the randomized groups (Bowden et al, 2000).

\section{Early Discontinuation for Depression}

The number of patients who suffered breakthrough depression during their participation in the maintenance, double- blind phase of the study is presented in Table 1. As previously reported, a lower percentage of divalproextreated $(6.4 \%, 12 / 187)$ than placebo-treated $(16.0 \%, 15 / 94)$ patients discontinued for depression $(P=0.017$ Fisher's exact test) (Bowden et al, 2000). The rate of early discontinuation because of depression for lithium $(9.9 \%$, 9/91) did not differ from that of placebo or divalproex. The same trend was observed when early discontinuation data were analyzed by SSRI use. Among those treated with a SSRI for breakthrough depression, a lower percentage of patients in the divalproex group $(9.8 \%, 4 / 41)$ discontinued early for depression than in the placebo group (45\%, $9 / 20, P=0.003$ Fisher's exact test) (Figure 1). Mean change from baseline in DSS score to the time of first SSRI use and rates of SSRI use did not differ in divalproex-, placebo-, and lithium-treated patients (Table 2). However, patients in the lithium group required an SSRI addition significantly sooner following randomization than those in the divalproex group (Table 2). The number of past depressive episodes $(\mathrm{OR}=1.17[1.02$, 1.34], $\mathrm{df}=1 P=0.025)$ and female gender $(\mathrm{OR}=1.78[1.07$, 2.95], $\mathrm{df}=1, P=0.026$ ) were predictors of SSRI use.

\section{Early Discontinuation for any Reason}

A lower percentage of divalproex-treated $(62 \%, 116 / 187)$ than lithium-treated $(76 \%, 69 / 91 ; P=0.03$. by Fisher's exact test) or placebo-treated $(75 \%, 71 / 94 ; P=0.05$ by Fisher's exact test) patients discontinued for any reason (Bowden et al, 2000). Similarly, the rate of early discontinuation for any reason was lower among patients in the divalproex group taking an SSRI than among patients in the placebo group taking an SSRI (56\% [23/41] vs 85\% [17/20], $P=0.043$ by Fisher's exact test). Rate of early discontinuation for any reason did not differ between the lithium and the SSRI group $(71.4 \%, 15 / 21)$ and the divalproex and SSRI groups or the placebo and SSRI groups.

Divalproex- and SSRI-treated patients remained in the study significantly longer than placebo- and SSRI-treated patients $(243.0 \pm 130.6$ vs $168.8 \pm 130.6, \mathrm{~F}=4.27 ; \mathrm{df}=1,79$, $P=0.044)$. The difference in length of time in the study between the divalproex/SSRI and placebo/SSRI groups was not attributable to mania relapse, as only one patient (in the divalproex group) had a manic episode while treated with an SSRI. The time in study prior to the addition of an SSRI

Table I Characteristics of Breakthrough Depression

\begin{tabular}{lccc}
\hline & $\begin{array}{c}\text { Divalproex } \\
(\mathbf{n = 1 8 7 )}\end{array}$ & $\begin{array}{c}\text { Placebo } \\
(\mathbf{n = 9 4 )}\end{array}$ & $\begin{array}{c}\text { Lithium } \\
(\mathbf{n}=\mathbf{9 1})\end{array}$ \\
\hline $\begin{array}{l}\text { Patients using an } \\
\text { antidepressant (SSRI) }\end{array}$ & $41(22 \%)$ & $20(22 \%)$ & $21(23 \%)$ \\
$\begin{array}{l}\text { Premature discontinuation for } \\
\text { depression }\end{array}$ & $12(6 \%)$ & $15(16 \%)$ & $9(10 \%)$ \\
$\begin{array}{l}\text { Depression not requiring } \\
\text { hospitalization } \\
\quad \text { Hospitalization for }\end{array}$ & 6 & 9 & 5 \\
$\begin{array}{l}\text { depression } \\
\quad \text { Suicide attempt }\end{array}$ & 3 & 6 & 2 \\
$\quad$ SADS-C suicide score $\geqslant 4$ & 2 & 2 & 2 \\
$\begin{array}{l}\text { Patients meeting one or both } \\
\text { criteria }\end{array}$ & $50(27 \%)$ & $26(28 \%)$ & $24(26 \%)$ \\
\hline
\end{tabular}

SSRI = selective serotonin reuptake inhibitor. 
was significantly greater for divalproex-treated patients than lithium-treated patients $(\mathrm{F}=4.65 ; \mathrm{df}=1,79, P=0.034)$, and the duration of time patients took an SSRI was longer for patients in the divalproex group compared with the placebo group $(P=0.054, \mathrm{~F}=3.84, \mathrm{df}=1,79) \quad($ Table 2$)$. Among patients treated with an SSRI, the mean DSS score at the last assessment prior to initiation of the antidepressant was consistently greater than that measured 2,4 , and 8 weeks (LOCF) thereafter. The decrease in the mean DSS score was consistently greater (up to five-fold) among patients in the active treatment groups who completed the trial as compared to those who prematurely discontinued their participation for any reason (Table 3). The mean MRS score at the last evaluation before the initiation of antidepressant treatment was $0.8,1.3$, and 5.8 for patients who completed the trial in the divalproex, placebo, and
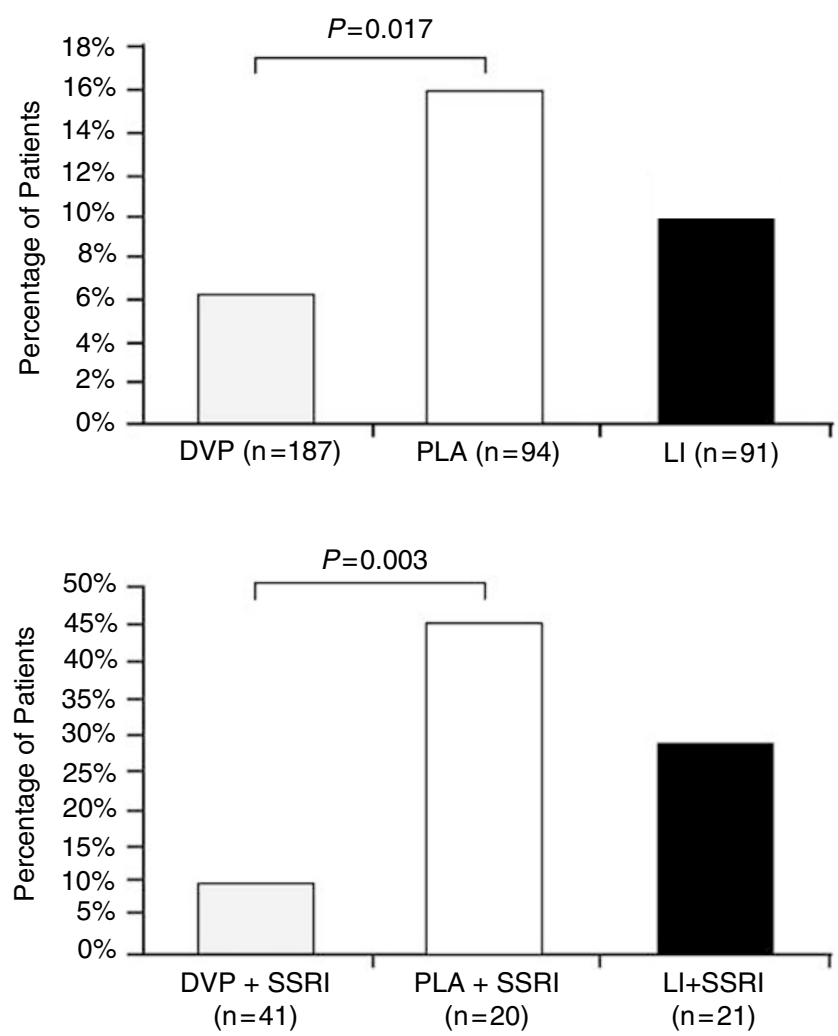

Figure I Proportion of patients with early discontinuation for depression (DVP = divalproex, $\mathrm{PLA}=$ placebo, $\mathrm{LI}=$ lithium, $\mathrm{SSRI}=$ selective serotonin reuptake inhibitors). lithium groups, respectively, and 1.5, 2.4, and 0.7 for patients who dropped out prematurely for any reason in the respective treatment groups.

\section{Predictors of Early Discontinuation for Depression}

Divalproex-treated patients were less likely than placebotreated patients to discontinue early for depression $(\mathrm{OR}=0.426$ [0.182, 0.997], $\mathrm{df}=1, P=0.049)$. Neither mean baseline DSS score $(4.6 \pm 4.6,4.5 \pm 4.6$, and $5.3 \pm 4.2$, respectively) nor mean baseline MRS score (3.4 \pm 3.7 , $3.2 \pm 3.7$, and $3.4 \pm 3.4$, respectively) had a differential predictive value on the rate of early discontinuation for depression with divalproex, lithium, or placebo.

For the whole sample, a higher number of previous depressive episodes $(\mathrm{OR}=1.30[1.055,1.598]$ per category, $\mathrm{df}=1, \quad P=0.014)$ and psychiatric hospitalizations $(\mathrm{OR}=1.68[1.100,2.577]$ per category, $\mathrm{df}=1, P=0.017)$ were associated with early discontinuation for depression.

\section{Time to Depressive Relapse}

Time to depressive relapse tended to be longer in the divalproex group than in the lithium group (Wilcoxon $\chi^{2}=3.11, \mathrm{df}=1, P=0.08$ ) (Bowden et al, 2000). For the subset of 142 patients who responded to divalproex during the open phase, time to depressive relapse was longer among those randomized to divalproex $(n=71)$ than to lithium ( $n=41$, Wilcoxon $\left.\chi^{2}=4.72, \mathrm{df}=1, P=0.03\right)$. Time to depression for placebo-treated patients $(n=37)$ did not differ from that of randomized divalproex- or lithiumtreated patients (Figure 2). Time to depression for patients who were open-phase lithium responders did not differ among groups ( $n=79$ divalproex, $n=32$ placebo, or $n=31$ lithium).

Among patients with previous psychiatric hospitalization, time to depressive relapse was longer in the divalproex group $(n=100)$ than the lithium group $(n=57$, Wilcoxon $\chi^{2}=5.93, \mathrm{df}=1, P=0.01$ ) (Figure 3 ), but did not differ between the divalproex and placebo $(n=56)$ groups (Wilcoxon $\chi^{2}=0.80, \mathrm{df}=1, P=0.37$ ). Among patients without prior hospitalization, no significant treatment differences existed for time to depression.

\section{Predictors of Depressive Relapse}

A higher lifetime number of manic and depressive episodes predicted depressive relapse (increase in $\mathrm{OR}=1.12$ [1.04,

Table 2 Characteristics of SSRI (Paroxetine or Sertraline) Use

\begin{tabular}{lcccl}
\hline & Divalproex & Placebo & Lithium & P-value \\
\hline Patients on SSRI & $41(21.9 \%)$ & $20(21.7 \%)$ & $21(23.3 \%)$ & NS \\
DSS score (mean \pm SE) & $(n=40)$ & $(n=18)$ & $(n=18)$ & NS \\
$\quad$ At baseline & $5.4 \pm 0.53$ & $5.6 \pm 0.78$ & $5.6 \pm 1.01$ & $\mathrm{NS}$ \\
$\quad$ Change to start of SSRI & $19.9 \pm 1.26$ & $20.3 \pm 2.28$ & $23.2 \pm 2.18$ & $\mathrm{LI}$ vs DVP $=0.034$ \\
Days in study before SSRI & $102.6 \pm 81.1$ & $68.1 \pm 73.2$ & $59.2 \pm 62.9$ & $\mathrm{~F}=4.65, \mathrm{df}=1,79$ \\
started (mean \pm SD) & $104.0 \pm 92.9$ & $56.2 \pm 75.2$ & $104.6 \pm 95.3$ & $\mathrm{DVP}$ vs PLA $=0.054, \mathrm{~F}=3.84, \mathrm{df}=1,79$ \\
Days on SSRI (mean \pm SD) & & & $\mathrm{LI}$ vs PLA $=0.088, \mathrm{~F}=2.99, \mathrm{df}=1,79$ \\
& & & \\
\hline
\end{tabular}

$\mathrm{DVP}=$ divalproex; PLA = placebo; LI = lithium; SSRI = selective serotonin reuptake inhibitors; SD = standard deviation; SE = standard error; NS = not significant. 
Table 3 Mean DSS Score in Patients Taking a Selective Serotonin Reuptake Inhibitor

\begin{tabular}{cccc}
\hline & Divalproex & Placebo & Lithium \\
\hline Patients who completed the trial & & & \\
Last assessment prior to SSRI & $n=18$ & $n=3$ & $n=6$ \\
& 22.7 & 16.3 & 26.3 \\
2 Weeks after start of SSRI & $n=7$ & $n=3$ & $n=6$ \\
& 12.4 & 19.3 & 11.7 \\
4 Weeks after start of SSRI & $n=17$ & $n=2$ & $n=5$ \\
& 11.1 & 11.5 & 9.6 \\
8 Weeks LOCF (end point) & $n=18$ & $n=3$ & $n=6$ \\
& 7.9 & 12.3 & 7.5 \\
& & & \\
Patients who dropped out for any reason & $n=22$ & $n=15$ & $n=15$ \\
Last assessment prior to SSRI & 27.5 & 23.5 & 25.5 \\
& $n=11$ & $n=12$ & $n=10$ \\
2 Weeks after start of SSRI & 24.8 & 19.0 & 23.7 \\
& $n=14$ & $n=11$ & $n=10$ \\
4 Weeks after start of SSRI & 13.9 & 13.5 & 20.6 \\
& $n=22$ & $n=15$ & $n=15$ \\
8 Weeks LOCF (end point) & 15.3 & 16.4 & 21.0 \\
\hline
\end{tabular}

$\mathrm{SSRI}=$ selective serotonin reuptake inhibitors.

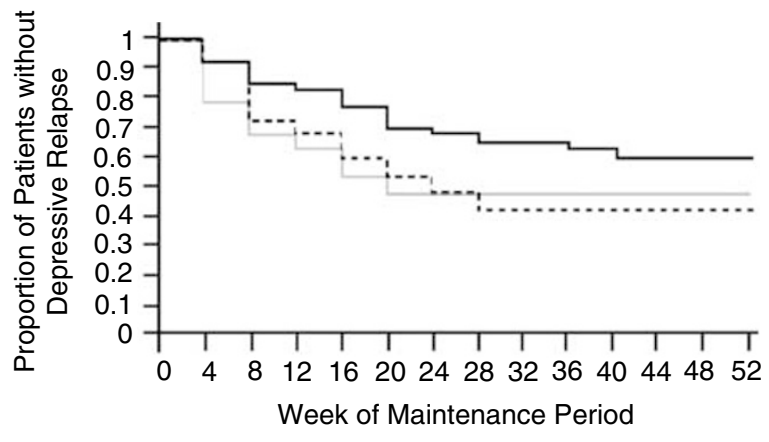

-..-Placebo $(n=37) \quad$ Divalproex $(n=71)$

\section{Lithium $(n=41)$}

Figure 2 Time to depression (Kaplan-Meier survival curves) in patients who were treated only with divalproex before randomization $(P=0.03$ for DVP vs LI, see text for details).

1.21] for every category increase, $\mathrm{df}=1, P=0.002$ ). Females were more likely than males to experience depressive relapse $(\mathrm{OR}=1.98[1.22,3.22], \mathrm{df}=1, P=0.006)$.

\section{Predictors of Worsening of Depressive Symptoms}

Worsening of depressive symptoms (measured by the mean change in DSS score from baseline) was positively related to the lifetime number of manic episodes (slope $=0.68, \mathrm{df}=1$, $P=0.015)$ and the number of psychiatric hospitalizations (slope $=1.46, \mathrm{df}=1, P=0.015)$. It was negatively related to baseline DSS score (slope $=-0.39, \quad \mathrm{df}=1, \quad P=0.002$ ). Therefore, the more manic episodes or hospitalizations patients had in their lifetime, the more likely they were to experience worsening of depressive symptoms during the maintenance phase. The mean DSS scores increased more among lithium-treated than in divalproex-treated patients (difference in mean change: $2.37, \mathrm{df}=1, P=0.04$ ).

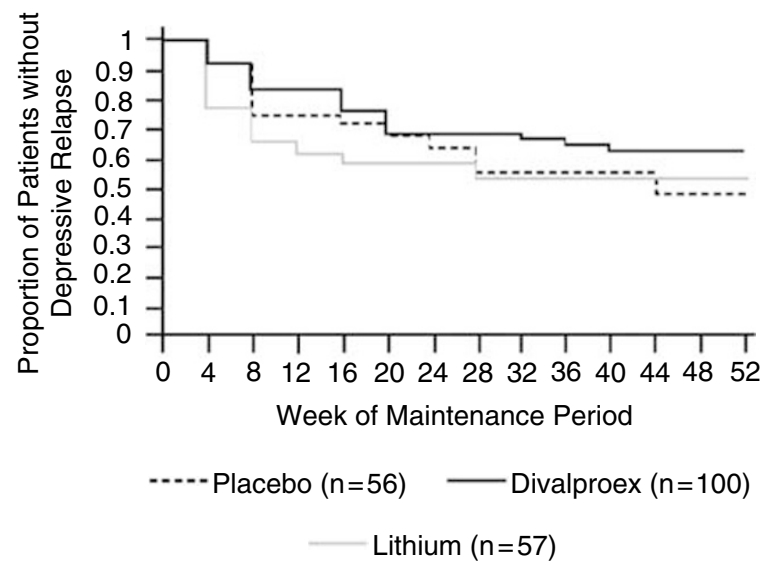

Figure 3 Time to depression (Kaplan-Meier survival curves) in patients with previous hospitalization for affective episode ( $P=0.0$ I for DVP vs LI, see text for details).

\section{DISCUSSION}

In these analyses of the maintenance efficacy of divalproex, lithium, or placebo for bipolar depression, several clinically relevant findings emerged. Fewer divalproex/SSRI-treated patients than placebo/SSRI-treated patients terminated early for depression. Relatedly, divalproex/SSRI-treated patients remained in the study longer and took SSRIs longer than placebo/SSRI-treated patients. Divalproex was more effective than lithium in delaying time to depressive relapse among patients who responded to divalproex in the open period. Divalproex was more effective than lithium in increasing time to depressive relapse in patients with an indication of more severe illness (patients with past psychiatric hospitalization). Divalproex-treated patients had less worsening of depressive symptoms than lithium-treated patients. Finally, severity of prestudy course of illness predicted worse outcome for all treatment groups.

The combination of divalproex and SSRI was an effective treatment for breakthrough depression. In contrast, SSRI without a mood stabilizer (divalproex) was ineffective. These are the first data from a randomized, blinded trial indicating that an antidepressant alone is inferior to an antidepressant plus a mood stabilizer in preventing breakthrough depression with bipolar disorder during maintenance treatment. The lithium and SSRI group was intermediate, but did not differ significantly from the placebo and SSRI or the divalproex and SSRI groups, perhaps because of Type II error caused by lack of high enough power in the placebo and lithium groups.

According to Kaplan-Meier analysis, time to depressive relapse was longer for divalproex-treated patients with previous psychiatric hospitalization, suggesting that divalproex may be more efficacious than lithium in maintenance treatment of more severe forms of bipolar illness. Better response to divalproex among patients who responded to divalproex in the open phase indicates that a positive acute antimanic response to divalproex may predict subsequent prophylaxis of depression with divalproex, but not with lithium. The patients who responded to lithium treatment in the open phase provided a similarly enriched sample to 
study the relative efficacy of randomization to continued lithium, compared to randomization to placebo or divalproex. No significant differences emerged, nor did numerical responses tend to favor the response of those randomized to lithium. In the light of these results, although limited by the smaller lithium sample size, the value of continuation of lithium from acute treatment for mania to maintenance treatment aimed at the prevention of depressive relapse requires further study. The duration of crossover from open phase to randomized medications did not affect the study outcome (Bowden et al, 2000).

History of psychiatric hospitalization had a discriminative effect on the efficacy of maintenance treatments, but no other baseline demographic, clinical, or prestudy clinical course variables had differential predictive value for response of depression to divalproex, lithium, or placebo. However, for the ITT sample, indices of severity (greater lifetime number of hospitalizations, manic episodes, and/or depressive episodes) predicted worse outcome across all treatment groups in terms of early discontinuation for depression, depressive relapse, and depressive symptom severity. We believe this is the first study to suggest that the lifetime number of manic episodes is associated with continuing depressive morbidity in bipolar disorder. This finding suggests that control (or lack of control) of mania may affect the depressive side of bipolar disorder. Supportive of this finding, others have observed that, during lithium treatment, a greater lifetime number of affective episodes (Gelenberg et al, 1989; Harrow et al, 1990; Gitlin et al, 1995; Tohen et al, 1990) or hospitalizations (O'Connell et al, 1991; Harrow et al, 1990) predicts more affective symptoms (O'Connell et al, 1991) or higher rate of affective relapse (Prien et al, 1974; Gelenberg et al, 1989; Harrow et al, 1990; Keller et al, 1992; Aagaard and Vestergaard, 1990). However, predictors for the prophylaxis of depressive morbidity in controlled maintenance studies have not been previously reported.

Female patients were at a greater risk for major depressive relapse and therefore were more likely than males to be treated with antidepressants. Thus, females seem more prone to bipolar depressive episodes and may need more vigilant management for early detection of impending depression, despite the fact that they may not have a greater risk for interepisodic depressive symptoms than males. Aagaard and Vestergaard (1990) also noted that females were less responsive to lithium treatment than were males.

Limitations of this study have been described in previous publications (Bowden et al, 1997, 2000; Baldessarini et al, 2000). To summarize, survival analysis of time to depressive relapse in the ITT sample showed no treatment differences. This may be explained by three factors. First, the a priori criteria for depressive (and for manic) relapse set for this study required a full depressive (and manic) episode (Bowden et al, 2000). The relatively stringent definition that we used lowers the number of failure events, thereby lowers power and less generalizable to clinical practice. Other recent maintenance studies in bipolar disorder have defined depressive relapse less stringently as time to the treating psychiatrist's decision that additional therapy for depression (or mania) was required (Calabrese et al, 2000; Bowden et al, 2003, Greil and Kleindienst, 1999). On the basis of these recent studies, defining mood failure events as the time of intervention increases the practicability of placebo-controlled maintenance studies and is consistent with clinical practice of endeavoring to intervene early.

Second, and relatedly, the proportion of placebo-treated patients relapsing with depression in this study $(28.3 \%)$ was apparently lower than in previous double-blind, placebocontrolled, parallel design studies of lithium (approximately 44-50\%) (Fieve et al, 1976; Prien and Klett, 1973b). Unlike the earlier lithium studies that abruptly discontinued lithium from stably maintained patients at the point of randomization, patients taking lithium in the open phase of this study were tapered off over a 2-week period, possibly reducing withdrawal-related relapse rates (Bowden et al, 2000). The low placebo relapse rate reduced the effect size, thereby decreasing the probability of detecting differences between the active treatment groups and the placebo group. Third, the rate of affective relapse for placebo-treated (but not lithium-treated) patients has been previously shown to continue increasing after 12 months (Prien et al, 1974); thus, a longer randomized period might have produced more power to show differences between response rates to active medications and placebo.

Negative findings regarding the efficacy of lithium $v s$ placebo must be viewed cautiously, especially in the light of the relatively low relapse rate on placebo in this study and continued evidence of maintenance efficacy of lithium in bipolar disorder (Gelenberg et al, 1989; Berghofer et al, 1996; Tondo et al, 1998; Bowden et al, 2003). Furthermore, clinical variables such as episode sequence (Kokopolus et al, 1980; Maj et al, 1989), frequency of mood cycling (Dunner and Fieve, 1974; Bowden 1995; Denicoff et al, 1997), presence of mood-congruent or -incongruent psychotic features of the index episode (Greil et al, 1998; Tohen et al, 1992), comorbid conditions (especially anxiety disorders) (Greil et al, 1998; Feske et al, 2000), and family history (Grof et al, 1994) may provide further explanation of the differential response to lithium and divalproex. Some of these may need to be described in future studies as potential explanatory factors of treatment response.

In summary, this study demonstrates that divalproex improves several dimensions of depression during maintenance treatment of bipolar I patients who had experienced a recent manic episode at the point of study entry and reduces the probability of depressive relapse, particularly in patients with a more severe course of illness.

\section{ACKNOWLEDGEMENTS}

This multicenter, collaborative trial was sponsored by Abbott Laboratories, North Chicago, Illinois.

The following members of the Divalproex Maintenance Study Group took part in this study: Paul E Alexander, MD, Psychiatric Foundation for Research and Education, Warwick, RI; Charles Bowden, MD, University of Texas Health Science Center, San Antonio, TX; Joseph RCalabrese, MD, Case Western Reserve School of Medicine, Cleveland, OH; Jeffery Clothier, MD, University of Arkansas Medical School, Little Rock, AR; Robert Cooke, MD, Clarke Institute of Psychiatry, Toronto, Canada; William Coryell, MD, 
University of Iowa Hospitals and Clinics, Iowa City, IA; James C-Y Chou, MD New York University School of Medicine, New York, NY; Scott Crow, MD, University of Minnesota Hospital, Minneapolis, MN; Pedro Delgado, MD, University of Arizona College of Medicine, Tucson, AZ; John Downs, MD, University of Tennessee, Memphis, TN; Dwight Evans, MD, University of Florida College of Medicine, Gainesville, FL (currently of University of Pennsylvania Medical Center, Philadelphia, PA); Arlene F Frank, MD, Brookside Hospital, Nashua, NH; Robert Gerner, MD, University of California Center for Mood Disorders, Los Angeles, CA; William J Giakas, MD, Rockford Psychiatric Medical Services, Rockford, IL; Ira David Glick, MD, Stanford University School of Medicine, Stanford, CA; Laszlo Gyulai, MD, University of Pennsylvania Medical Center, Philadelphia, PA; Robert MA Hirschfeld, MD, University of Texas Medical Branch, Galveston, TX; Steven Parker James, MD, Yorba Hills Medical Plaza, Yorba Linda, CA; Philip G Janicak, MD, Illinois State Psychiatric Institute, Chicago, IL; James W Jefferson, MD, Dean Foundation for Health, Research, and Education, Madison, WI; Paul E Keck, Jr, MD, University of Cincinnati College of Medicine, Cincinnati, OH; Barbara L Kennedy, $\mathrm{MD}, \mathrm{PhD}$, University of Louisville, Louisville, KY; K Ranga Rama Krishnan, MD, Duke University Medical Center, Durham, NC; Susan McElroy, MD, University of Cincinnati College of Medicine, Cincinnati, OH; B Raj Nakra, MD, Washington University School of Medicine, Saint Louis, MO; Henry A Nasrallah, MD, Ohio State University College of Medicine, Columbus, OH; Charles B Nemeroff, MD, PhD, Emory University School of Medicine, Atlanta, GA; William M Patterson, MD, Birmingham Research Group, Inc., Birmingham, AL; Frederick Petty, MD, PhD, University of Texas Southwestern Medical Center, Dallas, TX (Currently of Creighton University, Omaha, NE); Alan H Rosenbaum, MD, Comprehensive Psychiatric Services, Farmington Hills, MI; David Vincent Sheehan, MD, University of South Florida Psychiatry Center, Tampa, FL; Alan C Swann, MD, University of Texas Medical School at Houston, Houston, TX; Craig S Risch, MD, Medical University of South Carolina, Charleston, SC; Richard L Wang, MD, Milwaukee County Medical Complex, Milwaukee, WI; Adel Wassef, MD, University of Texas-Houston Health Science Center, Houston, TX; Richard H Weisler, MD, Raleigh, NC; Phillip Wilner, MD, Payne Whitney Psychiatric Clinic, New York City, NY; Patricia J Wozniak, Abbott Laboratories, North Chicago, IL.

Dr Gyulai is a consultant of Novartis, Bristol-Myers Squibb (BMS) and GlaxoSmithKline. He received grant support from GlaxoSmithKline, Abbott Laboratories, AstraZeneca, Eli Lilly and Company, Parke-Davis Pharmaceuticals and Bristol-Myers Squibb. He has been on the Speakers Bureau of GlaxoSmithKline, AstraZeneca, BMS, Abbott Laboratories and Janssen Pharmaceutica.

Dr Bowden is a consultant to Abbott Laboratories, Eli Lilly, GSK, Janssen, Ortho-McNeill, and Sanofi Synthelabo. He receives grant support from Abbott, Eli Lilly, Janssen, $\mathrm{NIMH}$, and the Stanley Foundation. He is on Speakers Bureaus of Abbott, GSK, Ortho McNeill, Astra Zeneca, and Sanofi Synthelabo.

Dr McElroy is a consultant to Abbott Laboratories and a member of the company's Speakers Bureau and Divalproex
Advisory Board. She has also received research grants from Abbott Laboratories and Eli Lilly and Company.

Dr Calabrese reports the following:

Sources of Funding: National Institutes of Mental Health; Abbott Laboratories; Ciba-Geigy; Merck; GlaxoSmithKline; Janssen Pharmaceutica; Lilly Research Laboratories; MacArthur Foundation; National Alliance for Research in Schizophrenia and Affective Disorders; Parke-Davis Pharmaceuticals; Robert Wood Johnson Pharmaceutical Research Institute; Sandoz Pharmaceutical Company; SmithKline Beecham Pharmaceuticals; Stanley Foundation; TAP Holdings, Inc; UCB Pharma; and Wyeth Ayerst.

Consulting Agreements/Advisory Boards: Abbott Laboratories; AstraZeneca; Bristol-Myers Squibb/Otsuka; Eli Lilly; GlaxoSmithKline; Janssen Cilag; Novartis; Parke Davis/ Warner Lambert; Robert Wood Johnson Pharmaceutical Research Institute; Shire Labs; TAP Holdings, Inc.; Teva Pharmaceuticals; and UCB Pharma.

Dr Petty has received grant support from Pfizer Inc., Eli Lilly and Company, Janssen Pharmaceutica, and Ortho McNeil Pharmaceuticals. He has served as a consultant for Bristol-Myers Squibb. Dr Petty has served on the Speakers' Bureau for Pfizer Inc., Eli Lilly and Company, Janssen Pharmaceutica, and Bristol-Myers Squibb.

Dr Swann has received grant support from Abbott Laboratories, GlaxoSmithKline, UCB Pharma, Bristol-Myers Squibb, Eli Lilly and Company, and Shire Laboratories. He has served as a consultant for Abbott Laboratories, Pfizer Laboratories, Shire Laboratories, UCB Pharma, GlaxoSmithKline, Novartis, Eli Lilly and Company, and BristolMyers Squibb. He has served on Speakers' Bureaus for Abbott Laboratories, Janssen Pharmaceutica, Novartis, GlaxoSmithKline, and Pfizer Laboratories.

Dr Chou reports the following:

Grant Support: Janssen Pharmaceutica; GlaxoSmithKline; Pfizer; Abbott Laboratories; Novartis; Ortho-McNeil; Merck; Otsuka; Bristol-Myers Squibb; Eli Lilly and Company; AstraZeneca; and Hoechst MarionRoussell.

Consultant: Janssen Pharmaceutica; GlaxoSmithKline; Pfizer; and Abbott Laboratories

Speakers Bureau: Abbott Laboratories; Janssen Pharmaceutica; GlaxoSmithKline; Pfizer; Ortho-McNeil; BristolMyers-Squibb; AstraZeneca; and Eli Lilly.

Dr Wassef has received grant support, served as a consultant, and has served on the Speakers' Bureau for Abbott Laboratories.

Dr Risch has consulted, received grant support, and is on the speakers' bureau of Pfizer Inc., Eli Lilly and Company, GlaxoSmithKline, Forest Laboratories, Sandoz, Abbott Laboratories, Astra Zeneca, Janssen Pharmaceutica, Shire, Bristol-Myers Squibb, and Searle.

Dr Hirschfeld reports the following:

Grants/Research Support: Abbott Laboratories; Bristol-Myers Squibb; GlaxoSmithKline; Organon Inc.; and Wyeth-Ayerst.

Consultant/Advisory Board: Abbott Laboratories; BristolMyers Squibb; GlaxoSmithKline; Forest Laboratories; Eli Lilly and Company; Pfizer, Inc.; Organon Inc.; Janssen Pharmaceutica; Wyeth-Ayerst; Sepracor; Novartis; and UCB Pharma.

Speakers Bureau: Abbott Laboratories; Bristol-MyersSquibb; Forest Laboratories; Eli Lilly and Company; Organon Inc.; and Pfizer; Inc. 
Dr Nemeroff reports the following:

Grants/Research: Abbott Laboratories; AstraZeneca; Bristol-Myers Squibb; Forest Laboratories; Janssen Pharmaceutica; Eli Lilly and Company; GlaxoSmithKline; NARSAD; NIMH; Organon; Pfizer Pharmaceuticals; Pharmacia-Upjohn; Stanley Foundation/NAMI; and Wyeth-Ayerst.

Consultant: Abbott Laboratories; Acadia Pharmaceuticals; AstraZeneca; Bristol-Myers Squibb; Cephalon Pharmaceuticals; Corcept; Cypress Biosciences; Forest Laboratories; GlaxoSmithKline; Janssen Pharmaceutica; Eli Lilly and Company; Merck; Mindsense; Neurocrine Biosciences; Novartis; Organon; Otsuka; Pharmacia-Upjohn; Sanofi; Somerset; Vela Pharmaceuticals; and Wyeth-Ayerst.

Speakers Bureau: Abbott Laboratories; AstraZeneca; Bristol-Myers Squibb; Eli Lilly and Company; Forest Laboratories; GlaxoSmithKline; Janssen Pharmaceutica; Organon; Pfizer Pharmaceuticals; and Wyeth-Ayerst.

Stockholder: Corcept.

Dr Keck is a consultant to, or member of the scientific advisory boards of: Abbott Laboratories, AstraZeneca Pharmaceuticals, Bristol-Myers Squibb, GlaxoSmithKline, Janssen Pharmaceutica, Eli Lilly and Company, Novartis, Ortho-McNeil, Pharmacia, Pfizer, Shire, and Wyeth-Ayerst. Dr Keck is a principal or coinvestigator on research studies sponsored by: Abbott Laboratories, AstraZeneca, GlaxoSmithKline, Elan, Eli Lilly and Company, Merck, Organon, Pfizer, and UCB Pharma.

Dr Evans has received grants/research support from Glaxo SmithKline. Dr Evans is a consultant to/on the Speakers' Bureau of Abbott Laboratories, AstraZeneca, Bristol-Myers Squibb, Eli Lilly and Company, Forest Laboratories, Janssen Pharmaceutica, Novartis, Organon, Pfizer Inc., Glaxo SmithKline, Somerset, TAP Pharmaceuticals, Inc., and Wyeth Ayerst.

Dr Wozniak is an employee of Abbott Laboratories.

\section{REFERENCES}

American Psychiatric Association (1994). Diagnostic and Statistical Manual of Mental Disorders, 4th edn American Psychiatric Association: Washington, DC.

Aagaard J, Vestergaard P (1990). Predictors of outcome in prophylactic lithium treatment: a 2 -year prospective study. $J$ Affect Disord 18: 259-266.

Altshuler LL, Post RM, Leverich GS, Mikalauskas K, Rosoff A, Ackerman L (1995). Antidepressant-induced mania and cycle acceleration: a controversy revisited. Am J Psychiatry 152: 11301138.

Baldessarini RJ, Tohen M, Tondo L (2000). Maintenance treatment in bipolar disorder [comment]. Arch Gen Psychiatry 57: 490-492.

Bauer MS, Calabrese J, Dunner DL, Post R, Whybrow PC, Gyulai L et al (1994). Multisite data reanalysis of the validity of rapid cycling as a course modifier for bipolar disorder in DSM-IV. Am J Psychiatry 151: 505-515.

Berghofer A, Kossmann B, Muller-Oelinghausen B (1996). Course of illness and pattern of recurrence in patients with affective disorders during long-term lithium prophylaxis: a retrospective analysis over 15 years. Acta Psychiatr Scand 93: 349-354.

Bowden CL (1995). Predictors of response to divalproex and lithium. J Clin Psychiatry 3: 25-30.

Bowden CL, Brugger AM, Swann AC, Calabrese JR, Janicak PG, Petty $\mathrm{F}$ et al (1994). Efficacy of divalproex $v s$ lithium and placebo in the treatment of mania. JAMA 271: 918-924.
Bowden CL, Calabrese JR, McElroy SL, Gyulai L, Wassef A, Petty F et al (2000). A randomized, placebo-controlled 12-month long trial of divalproex and lithium in the treatment of outpatients with bipolar I disorder. Arch Gen Psychiatry 57: 481-489.

Bowden CL, Calabrese JR, Sachs G, Yatham YN, Asghar SA, Hompland $\mathrm{M}$ et al (2003). A placebo-controlled 18-month trial of lamotrigine and lithium maintenance treatment in recently manic or hypomanic patients with bipolar I disorder. Arch Gen Psychiatry 60: 392-400.

Bowden CL, Swann AC, Calabrese JR, McElroy SL, Morris D, Petty $\mathrm{F}$ et al (1997). Maintenance clinical trials in bipolar disorder: design implications of the divalproex-lithium placebo study. Psychopharmacol Bull 33: 693-699.

Calabrese JR, Delucchi GA (1990). Spectrum of efficacy of valproate in 55 patients with rapid cycling bipolar disorder. Am J Psychiatry 147: 431-434.

Calabrese JR, Suppes T, Bowden CL, Sachs GS, Swann AC, McElroy SL et al (2000). A double-blind, placebo-controlled, prophylaxis study of lamotrigine in rapid-cycling bipolar disorder. J Clin Psychiatry 61: 841-850.

Denicoff KD, Smith-Jackson EE, Disney ER, Ali SO, Leverich GS, Post RM (1997). Comparative prophylactic efficacy of lithium, carbamazepine, and the combination in bipolar disorder. J Clin Psychiatry 58: 470-478.

Draper NR, Smith H (1981). Applied Regression Analysis. Wiley \& Sons: New York, NY.

Dunner DL, Fieve RR (1974). Clinical factors in lithium carbonate prophylaxis failure. Arch Gen Psychiatry 30: 229-233.

Emrich HM, Gunther R, Dose M (1983). Current perspectives in the pharmacopsychiatry of depression and mania. Neuropharmacology 22: 385-388.

Endicott J, Spitzer RL (1978). A diagnostic interview: the schedule for affective disorders and schizophrenia. Arch Gen Psychiatry 35: $837-844$

Feske U, Frank E, Mallinger AG, Houck PR, Fagiolin A, Shear MK et al (2000). Anxiety as a correlate of response to the acute treatment of bipolar I disorder. Am J Psychiatry 157: 956-962.

Fieve RR, Kumbaraci T, Dunner DL (1976). Lithium prophylaxis of depression in bipolar I, bipolar II, and unipolar patients. Am J Psychiatry 133: 925-929.

Gelenberg AJ, Kan JM, Keller MB, Lavori P, Rosenbaum JF, Cole K et al (1989). Comparison of standard and low serum levels of lithium for maintenance treatment of bipolar disorder. $N$ Eng $J$ Med 321: 1489-1493.

Ghaemi SN, Goodwin FK (2001). Divalproex vs lithium in the treatment of bipolar disorder: a naturalistic 1.7-year comparison. J Affect Disord 65: 281-287.

Gitlin MJ, Swendsen J, Heller TL, Hammen C (1995). Relapse and impairment in bipolar disorder. Am J Psychiatry 152: 1635-1640.

Goodwin FK, Jamison KR (1990). Manic-Depressive Illness. Oxford University Press, Inc.: New York, NY.

Greil W, Kleindienst N (1999). Lithium versus carbamazepine in the maintenance treatment of bipolar II disorder and bipolar disorder not otherwise specified. Int Clin Psychopharmacol 14: 283-285.

Greil W, Kleindienst N, Erazo N, Muller-Oerlinghausen B (1998). Differential response to lithium and carbamazepine in the prophylaxis of bipolar disorder. J Clin Psychopharmacol 18: 455460.

Grof P, Alda M, Grof E, Zvolsky P, Walsh M (1994). Lithium response and genetics of affective disorders. J Affect Disord 32: 85-95.

Harrow M, Goldberg JF, Grossman LS, Meltzer HY (1990). Outcome in manic disorders: a naturalistic follow-up study. Arch Gen Psychiatry 47: 665-671.

Keller MB, Lavori PW, Kane JM (1992). Subsyndromal symptoms in bipolar disorder. A comparison of standard and low serum levels of lithium. Arch Gen Psychiatry 49: 371-376. 
Kokopolus A, Reginaldi D, Laddomada P, Floris G, Serra G, Tondo L (1980). Course of manic-depressive cycle and changes caused by treatments. Pharmacopsychiatry 13: 156-167.

Maj M, Pirozzi R, Kemali D (1989). Long-term outcome of lithium prophylaxis in patients initially classified as complete responders. Psychopharmacology 98: 535-538.

Maj M, Pirozzi R, Magliano L, Bartoli L (1998). Long-term outcome of lithium prophylaxis in bipolar disorder: a 5-year prospective study of 402 patients at a lithium clinic. Am J Psychiatry 155: 3035.

McElroy SL, Keck Jr PE, Pope Jr HG, Hudson JI (1988). Valproate in the treatment of rapid-cycling bipolar disorder. $J$ Clin Psychopharmacol 8: 275-279.

O'Connell RA, Mayo JA, Flatow L, Cuthbertson B, O'Brien BE (1991). Outcome of bipolar disorder on long-term treatment with lithium. Br J Psychiatry 159: 123-129.

Petty F, Kram M, Davis LL, Nugen A, Bollig M, Gajewski V et al (1999). Valproate treatment of bipolar depression. Proceedings of NCDEU Annual meeting 1999: 6.

Prien RF, Caffey EM, Klett CJ (1973a). Prophylactic efficacy of lithium carbonate in manic-depressive illness. Report of the Veterans Administration and National Institute of Mental Health collaborative study group. Arch Gen Psychiatry 28: 337-341.

Prien RF, Klett CJ (1973b). Lithium carbonate and imipramine in prevention of affective episodes. A comparison in recurrent affective illness. Arch Gen Psychiatry 29: 420-425.

Prien RF, Caffey EM, Klett CJ (1974). Factors associated with treatment success in lithium carbonate prophylaxis. Report of the Veterans Administration and National Institute of Mental
Health collaborative study group. Arch Gen Psychiatry 31: 189192.

Puzynski S, Klosiewicz L (1984). Valproic acid amide as a prophylactic agent in affective and schizophrenic disorders. Psychopharmacol Bull 20: 151-159.

SAS Institute I (1989). SAS/STAT® User's Guide, Version 6, Vol. 2 SAS Institute, Inc.: Cary, NC.

Spitzer RL, Williams JBW, Gibbons M, First MB (1990). Structured Clinical Interview for the DSM-IIIR. American Psychiatric Press, Inc.: Washington, DC.

Swann AC, Bowden CL, Calabrese JR, Dilsaver SC, Morris DD (1999). Differential effect of number of previous episodes of affective disorder on response to lithium or divalproex in acute mania. Am J Psychiatry 156: 1264-1266.

Swann AC, Bowden CL, Calabrese JR, Dilsaver SC, Morris DD (2000). Mania: differential effects of previous depressive and manic episodes on response to treatment. Acta Psychiatr Scand 101: 444-451.

Tohen M, Tsuang MT, Goodwin DC (1992). Prediction of outcome in mania by mood-congruent or mood-incongruent psychotic features. Am J Psychiatry 149: 1580-1584.

Tohen M, Watemaux CM, Tsuang MT (1990). Outcome in mania: a four year prospective follow-up of 75 patients utilizing survival analysis. Arch Gen Psychiatry 47: 1106-1111.

Tondo L, Baldessarini RJ, Hennen J, Floris G (1998). Lithium maintenance treatment of depression and mania in bipolar I and bipolar II disorders. Am J Psychiatry 1555: 638-645.

Zarate CAJ, Tohen M, Baraibar G, Kando JC, Mirin J (1995). Prescription trends of antidepressants in bipolar depression. $J$ Clin Psychiatry 56: 260-264. 